\title{
VILA UNIÃO: BAIRRO, MEMÓRIAS E TERRITORIALIZAÇÃO
}

- NILDEMAR PEREIRA DA SILVA*

- NILSON ALMINO DE FREITAS ${ }^{\dagger}$

Resumo: O presente trabalho apresenta a história de ocupação do bairro Vila União, Sobral-CE, a partir das memórias de seus moradores, pensando suas agências na territorialização do lugar. Assim, pretende-se identificar as vivências e as relações de pertencimento dos moradores com 0 bairro a partir de suas narrativas. A metodologia utilizada foi pesquisa bibliográfica, de campo e, especialmente, a história oral. Por fim, mesmo diante das dificuldades enfrentadas pelos moradores do bairro, é perceptível em suas narrativas os laços de afetividade com o meio em que vivem, apesar dos critérios para justificar essa afetividade serem variados.

Palavras-chaves: Bairro. Territorialização. Memórias. História oral. região.

\section{Introdução}

A presente pesquisa apresenta o processo de ocupação, territorialização do bairro Vila União, bairro periférico de Sobral - CE e pretende identificar a relação de pertencimento da comunidade com o lugar. À princípio, o artigo apresenta um breve histórico do município de Sobral fundamentado em documentos oficiais, porém a metodologia principal do trabalho é a história oral, especialmente quando se fala aqui do bairro. Pensar as temporalidades marcadas nas histórias contadas pelos narradores individuais favorece ao geógrafo perceber que o território construído e a relação entre a definição de lugar, assim como o vínculo com uma determinada forma de conceber a 
identidade local, seguem um fluxo muito pouco coerente, bastante móvel e complexo de agências que devem ser pensadas como construções criativas que transformam e dão dinâmica rizomática ao espaço.

É importante frisar que o enfoque aqui é a agência do narrador individual. Como aponta Portelli (1997), a narrativa não pode ser vista dissociada do narrador. Sua narrativa expressa o desejo que aciona a agência que cria o lugar, o território e a desterritorialização, dinamizando o espaço geográfico.

As narrativas foram selecionadas a partir do documentário "Vida e Bairro Vila União"1 e de entrevistas do acervo do Laboratório das Memórias e das Práticas Cotidianas - $\mathrm{LABOME}^{2}$.

A entrevista, sem dúvidas, é uma metodologia que aproxima o pesquisador do sujeito que faz o território. Assim, possibilita dar visibilidade à história individual, obrigando o pesquisador a adotar um enfoque que foge à ideia de se interpretar discursos que parecem ser representativos de um coletivo abstrato. O entendimento aqui usado é de que a narrativa mostra que o indivíduo é ativo na construção desta idealização, não sendo apenas um replicante de representações coletivas. Ele utiliza de recursos linguísticos e de práticas de espaço que fogem a uma padronização estável do território. Ao mesmo tempo o respeita, o reforça e o modifica, de acordo com o contexto que fala ou age. Isso quer dizer que o indivíduo além de ser um mero reprodutor de representações sociais coletivas, também não fala de fatos objetivos. Ele apreende, usa e recria o espaço de acordo com seus desejos e competências, tendo participação ativa no movimento de territorialização e identificação de um coletivo. Conforme Portelli (1997, p.31), “entrevistas sempre revelam eventos desconhecidos ou aspectos desconhecidos de eventos conhecidos: elas sempre lançam nova luz sobre áreas inexploradas da vida diária das classes não hegemônicas”. Podemos acrescentar que, mesmo sendo de classes hegemônicas, os indivíduos não pensam sempre da mesma forma sobre o território que ocupam, mostrando também dissensos e conflitos internos entre seus pares.

As entrevistas utilizadas como fontes neste artigo foram realizadas em mais de um encontro, e os moradores foram os sujeitos protagonistas no processo. Nessa perspectiva, o território passa a ser visto como elemento existencial, como pensaria 
Deleuze (1997), pois caracteriza do ponto de vista individual o campo da segurança e do vínculo identitário. Mas, não podemos negar que também demonstra uma insegurança na defesa de fronteiras que marcam distâncias em relação a um "outro" que faz parte do território vizinho que pode ser um “inimigo", já que é "diferente”. A ideia de território nas fontes individuais acaba mostrando o investimento íntimo no espaço e no tempo para se proteger do caos, buscando unidade com outros que seriam entendidos pela pessoa como seus aliados. Não é um investimento somente simbólico e afetivo. É também material, portanto. O território, entretanto, por não mostrar segurança plena no seu traçado simbólico, afetivo e material, apesar de tentar falar de uma identidade, está acompanhado de linhas de fuga, de um fora e de um dentro, de desterritorialização, portanto, zona de experiência, de angústias, vergonha e inibição, ao mesmo tempo em que tenta criar conforto, confiança e desenvoltura.

No caso da territorialização que é a agência para invenção do território (espaço de conflitos, diferenças e movimentos múltiplos), quando o entrevistado tende a falar do lugar estável desejado, o leitor precisa entender, como aponta Portelli (1997, p. 35), ser fundamental “[ $\ldots$.$] que o pesquisador "aceite” o informante e dê prioridade ao que$ ela ou ele deseje contar e dê preferência ao que o pesquisador quer ouvir, reservando algumas questões não respondidas para mais tarde ou para outra entrevista.” É um momento de diálogo entre dois seres humanos que minimamente tentam entender um ao outro.

A história oral estabelece uma relação original entre o geógrafo e os agentes da territorialização do espaço, entendendo aqueles que fazem a geografia do lugar como atores concretos portadores de subjetividades e materialidades. Assim, além de conhecer o processo de ocupação do bairro Vila União, busca-se identificar a relação de afetividade da população com o bairro por meio da história oral assim como suas repercussões materiais, conflitos e diferenças.

Por outro lado, apesar de um lugar específico dentro da cidade, a narrativa é uma espécie de segmentação de falas que contam a territorialização em Sobral e, no caso específico do presente artigo, um bairro da cidade. Pensando esta inserção na cidade mais ampla e, ao mesmo tempo, fuga de uma simples inclusão em um lugar mais amplo, já que falam de especificidades, é preciso fazer uma breve incursão, mesmo que superficial, nas espacialidades e temporalidades de Sobral para entrarmos e percebemos as fugas e entradas do bairro Vila União em espaços e tempos mais amplos. 


\section{Sobral: A "Princesa" Do Norte Cearense}

Como o bairro Vila União pertence a Sobral e surgiu no contexto da expansão deste município é pertinente fazer uma breve descrição cronológica da cidade. Sobral é uma cidade média com população de 188.222 habitantes, segundo o censo do IBGE de 2010. Situada na porção noroeste do Ceará, entre as coordenadas de $3^{\circ} 41^{\prime} 10^{\prime \prime}$, latitude sul, e $40^{\circ} 20^{\prime} 59^{\prime \prime}$ de longitude oeste, a $230 \mathrm{~km}$ da capital Fortaleza. A cidade apresenta como codinome "Princesa do Norte Cearense" devido a relevância econômica no contexto regional.

Historicamente, é comum pensar a gênese das cidades como estando intrinsecamente vinculada à presença de recursos hídricos, rotas comerciais, posição e localização geográfica, dentre outros fatores (SPOSITO, 2000). Sobral não foge a regra, pois, na versão da história que parte das agências do colonizador, tem sua origem associada a uma fazenda de gado às margens do rio Acaraú, na depressão sertaneja.

O processo de ocupação do colonizador e a organização do território cearense em favor dos portugueses se iniciaram no século XVII, período em que se estava explorando o litoral nordestino. Todavia, diferentemente de outros estados, o Ceará teve a ocupação realizada do interior para o litoral, associada à pecuária extensiva, que migrou de outros estados da região Nordeste, em especial de Pernambuco e Bahia, acompanhando o trajeto dos rios (HOLANDA, 2007).

Nesse contexto, surgiu a fazenda Caiçara, em 1742, nas margens do rio Acaraú. A referida fazenda propiciou a formação de um núcleo de povoamento com o mesmo nome - Caiçara. Em 1773, o povoado passou à categoria de vila, a Vila Distinta e Real de Sobral, quando conquistou o direito de eleger "seus representantes". Posteriormente, a vila adquiriu status de cidade acompanhando o contexto estadual, em 1841.

Cabe frisar que a influência religiosa e, principalmente, econômica da Igreja foi condicionante para o rápido crescimento inicial da atual cidade de Sobral. A construção da igreja matriz atraiu a sociedade, influenciada pela forte religiosidade local, para a proximidade da igreja. Consequentemente os comerciantes e as unidades de abastecimentos foram atraídos, não necessariamente pela religiosidade, mas pelo adensamento populacional nas margens da igreja matriz (JÚNIOR, 2010). 
Outra atividade que colaborou significativamente para a formação e desenvolvimento de Sobral foi, sem dúvidas, a produção de algodão, em especial no século XIX. Além do cultivo de algodão, a cidade também se destacou no beneficiamento e distribuição do produto. Um empreendimento relevante nesse processo foi Companhia de Fiação e Tecidos Ernesto Deocleciano. Segundo Sales (2011, p.1), "foi fundada por dois sócios, Ernesto Deocleciano de Albuquerque, cearense, nascido em Aracati, mas residindo em Sobral, exportador e beneficiador de algodão, e Cândido José Ribeiro, industrial do ramo têxtil no Maranhão”.

A situação geográfica de Sobral também impulsionou a expansão da cidade, pois, além de estar próxima aos portos de Acaraú e Camocim, era passagem obrigatória para quem penetrasse o oeste do Ceará. Outro fato que contribuiu para o fenômeno da expansão urbana de Sobral foi a implantação da linha férrea no Ceará, que teve seu primeiro trecho construído em 1870 e depois ampliado em 1877. Segundo Holanda (2007, p. 92):

A rede ferroviária do estado era formada por duas linhas principais, a linha Sul, que ligava Fortaleza à região do Cariri e com o Estado da Paraíba e daí com os demais estados do Nordeste. E a linha Norte, que partia de Sobral, interligada a Camocim e a Crateús, quando ampliada, passa a ligar Sobral com Teresina no Piauí. O advento da ferrovia propiciou um maior crescimento de alguns núcleos urbanos cearenses, como Fortaleza, Iguatu, Crato e Sobral (Holanda, 2007, p. 92)

$\mathrm{Na}$ década de 1920, Sobral teve seu papel de protagonista afetado negativamente pela seca e o crescimento de Fortaleza. Para superar a crise, a cidade investiu na implantação de indústrias de beneficiamento de produtos locais, dentre eles o algodão. Sobral passou por profundas transformações na segunda metade do século $\mathrm{XX}$, incorporando novas atividades no seu território, como a indústria e revitalizando seu papel no controle regional através da concentração de equipamentos no setor terciário. Nesse contexto, a cidade também vivencia um processo de "embelezamento", ou melhor, o centro da cidade, Sobral. Para Freitas, Sobral:

É uma cidade que teve seu centro urbano tombado como Patrimônio Histórico Nacional em 1999 [...] e passou por um processo de "revitalização" de espaços no entorno do sítio histórico, tendo em vista tornar o centro-monumento iluminado e visível, reforçando uma ideia de "resgate" de uma tradição local (Freitas, 2010, p.186) 
Desde o final do século XX, a princesa do Norte tem vivenciado um processo de urbanização, acompanhando a tendência nacional, investimentos nas áreas elitizadas e implantação de bairros nobres. Em contrapartida, expeliu os migrantes que vinham em busca de uma "vida melhor" em cidade de maior porte que as suas, de origem, indo morar em áreas periféricas, já que o "sonho de uma vida melhor" não foi realizado. São espaços sem infraestrutura e saneamento básico, pois a ocupação nem sempre é promovida pela racionalização e planejamento habitacional do poder público, mas por ocupações promovidas pelos movimentos populares, assim como de políticos locais. Nesse contexto, foram ocupados alguns espaços periféricos, como o bairro Vila União. O que chama à atenção é que, no caso desse bairro, surgiu com planejamento urbano feito pelo movimento que organizou a ocupação, pelo menos no que se refere ao arruamento e organização dos lotes, formando quadrados como um tabuleiro de xadrez. Era comum ocupações ocorrerem sem esta preocupação, o que provoca um diferencial, segundo as fontes orais registradas. Segue relatos sobre o bairro.

\section{Conhecendo o Bairro Vila União}

$\mathrm{Na}$ sociedade estratificada em classes verificam-se diferenças sociais no que concerne ao acesso aos bens e serviços produzidos pelo capital. Segundo Corrêa (1989, p.29), "a habitação é um desses bens cujo acesso é seletivo: parcela enorme da população não tem acesso, quer dizer, não possui renda para pagar o aluguel de uma habitação decente, e, muito menos, comprar um imóvel”.

No mundo capitalista as diferenças sociais são marcantes e são refletidas na organização territorial, especialmente no espaço urbano. Nas cidades é visível a segregação espacial, pois as pessoas de renda elevada conseguem ter acesso a determinadas regiões selecionas no espaço da cidade para habitar onde prevalece uma atenção maior por parte das políticas de urbanização. Já os grupos sociais excluídos são obrigados a habitar territórios periféricos, sem as mesmas condições estruturais, como é o caso do bairro Vila União, localizado no noroeste de Sobral (figura 1). 


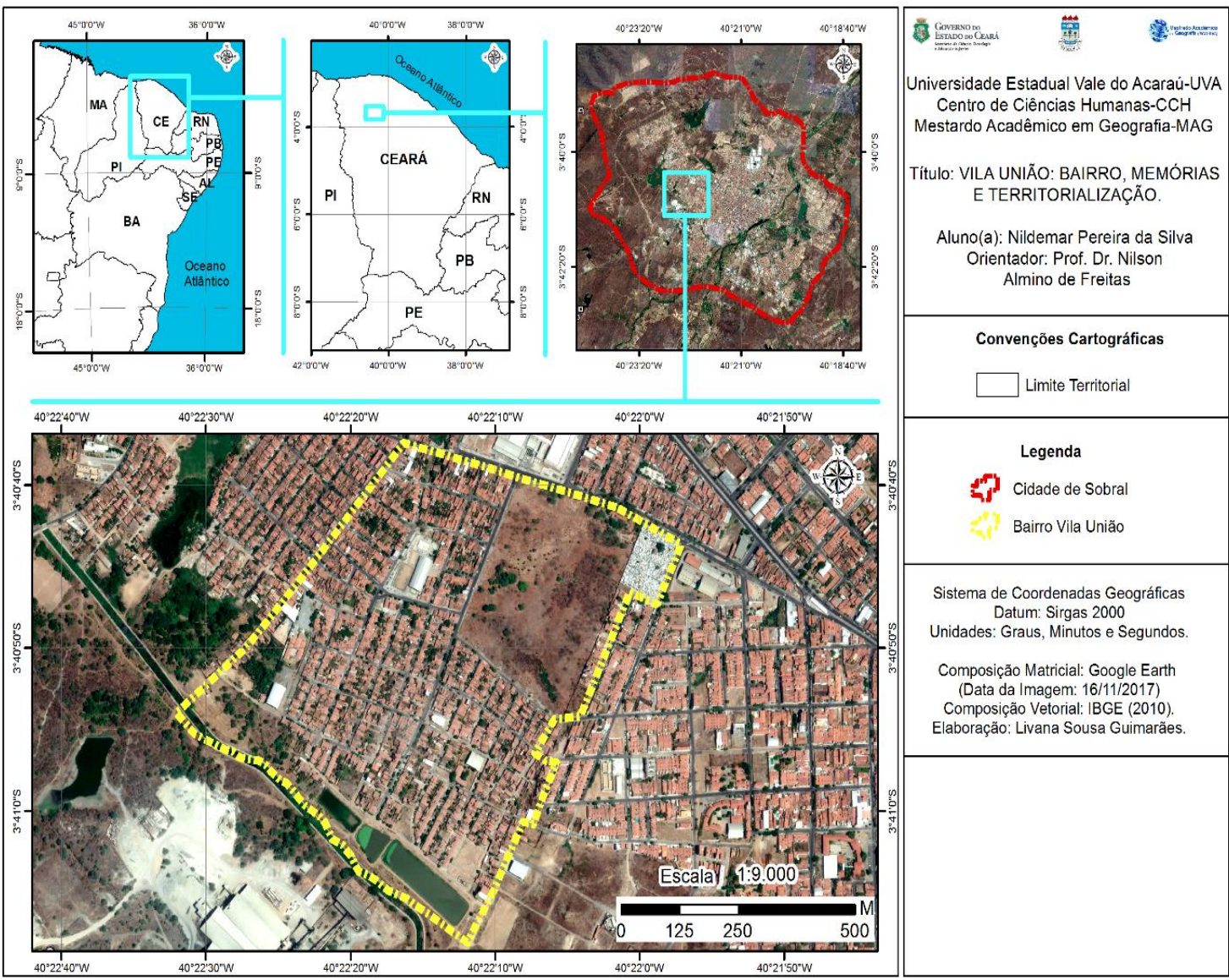

Figura 01 - Mapa da localização do bairro Vila União, Sobral-CE.

Fonte: Guimarães (2018); Silva (2018); (GOOGLE EARTH (2018))

É na produção de bairros periféricos, em terrenos públicos ou privados ocupados, que grupos sociais excluídos se tornam, efetivamente, agentes modeladores, produzindo seu próprio espaço. A produção desde espaço é uma forma de resistência e sobrevivência de grupos sociais, em uma sociedade excludente, migrantes do campo e desapropriados de áreas urbanas que passaram por um processo de "revitalização" (CORRÊA, 1989).

Para se conhecer a história da ocupação do bairro, como já dito, foram analisadas entrevistas realizadas com moradores pelos membros do LABOME. As entrevistas foram coletadas no contexto da produção do documentário "Vida e Bairro Vila União", realizado pelo LABOME, sendo entrevistadas pessoas que apresentavam laços afetivos com a história do bairro e que fizeram parte do processo de ocupação.

Cabe frisar, que foram valorizadas as histórias de vida dos interlocutores visando uma maior aproximação entre o pesquisador e o sujeito da territorialização do espaço geográfico em foco. Para Portelli: 
Os entrevistados estão sempre, embora talvez discretamente, estudando os entrevistadores que os "estudam". Os historiadores podem reconhecer este fato e tirar vantagens, em vez de experimentar eliminá-lo em razão de uma neutralidade impossível (e talvez desejável) (PORTELLI, 1997, p. 36)

Pensa-se, aqui, que não só o historiador, como informa o autor, pode entender estas fontes como resultado de diálogo onde ambos, entrevistador e entrevistado, agem na construção da narrativa, mas também o geógrafo, pois, como já dito, a narrativa não é somente uma expressão simbólica do espaço, é também uma agência, é criativa e territorializa, ao mesmo tempo em que desterritorializa. Começa-se, aqui, por dois entrevistados: Emanuel Rodrigues de Souza (Maneco) e Osvaldo Aguiar (ambientalista). Ambos informam que tiveram papel relevante na gênese do bairro, pois foram eles que arquitetaram a ocupação e organização inicial da Vila União.

Conforme Maneco (2005), em 1992, aproximadamente às 10 horas, ele recebeu a visita de um amigo do PT (Partido dos Trabalhadores), o Osvaldo Aguiar, para conversar sobre política. Nessa ocasião, Maneco relatou a sua preocupação com uma população do "Pantanal” do Alto da Brasília, atual conjunto Cesário Barreto Lima, que estava desabrigada por conta da inundação da lagoa presente no bairro (a Lagoa da Fazenda).

Ainda nessa visita, Osvaldo Aguiar falou para Maneco sobre um terreno da união que estava abandonado:

Eu ouvi uma conversa lá e tal que eles iam fazer, ocupar a fazenda e tal aquela coisa, aí eu fui "pra"* uma reunião na comunidade aí eu disse: Maneco eu sei "pra" onde é que nós vamos "né", ali no "Mucambinho" ali tem uma terra lá cara que é da União uma terra que é pública e tal "vamo" ver o que a gente pode fazer. Aí deu um insight "né vamo" ocupar e "vamo" levar esse pessoal aí começamos a planejar a comunidade discutindo com o pessoal e aí olha é o seguinte em vês de vocês ficarem aqui e tal e alugar casa, não ter "pra” onde ir, vocês topa ocupar uma área, aí fomos trabalhando o imaginário das pessoas "né" de ocupação "né" o quê que significa ocupação que a gente já tinha já noção "né”, quais são os problemas, os riscos que é de ocupação, fomos preparando as pessoas "pra” ocupação (OSVALDO AGUIAR, 2009, p. 43) 
Maneco, ao tomar conhecimento da existência de um terreno público desocupado, ficou entusiasmado com a possibilidade de ocupar e construir um conjunto habitacional, solucionando o problema da população sem moradia. Conforme Maneco:

Quando o Osvaldo me contou essa história caiu a sopa no mel (risos); aí foi como se fosse um estalo, eu fiquei do tamanho dessa casa aqui, eu lá em cima, porra nós vamos fazer... coragem, coragem 'nós vamos ocupar, tu topa? você sabe onde é?', o Osvaldo: 'sei!' (MANECO, 2005, p. 42)

Oswaldo e Maneco visitaram a área que seria ocupada, fizeram uma estimativa da quantidade de famílias que comportariam na área, fizeram planta de como seria o arruamento e organizaram os lotes. Conforme Osvaldo Aguiar:

Enquanto isso, eu fui com o Maneco "pra" ver esse terreno "pra" gente fazer um mapeamento da região, fazer um plano lá, que a gente não queria fazer uma favela "né", com uma visão, essa visão que o Maneco tinha da Construção Civil (OSVALDO AGUIAR, 2009, p. 44).

Conforme Maneco (2005, p. 34), "a dimensão do terreno, 6 m que eu tirei aqui pelo meu terreno, aqui dá $6 \mathrm{~m}$, por 15 de comprimento, por 30 de comprimento; a rua da Vila União foi toda tirada pela rua daqui de frente, a mesma dimensão de 12 m [...]”. De acordo com as entrevistas, foi o próprio Maneco que fez a planta inicial do bairro, pensando em futuro arruamento e organização dos lotes, e também criou o nome conjunto habitacional bairro Vila União, Maneco:

Foi eu que fiz o'croquis'. E toda a modéstia, dei o nome porque, aí vem a influência, porque eu tava certo do que eu queria né, porque o que a gente tava querendo, claro que o Osvaldo foi um parceiro no sentido de dar informação de entrar na briga e concordar com aquilo, com a proposta, a proposta que foi dada, por isso que digo, partiu de mim a ideia, por que Vila União? Primeiro não tinha um bairro com o nome de Vila União; segundo, porque era a união das pessoas em torno de um bairro; terceiro, porque a gente pensava que era um terreno da União (risos), essas razões... (MANECO, 2005, p. 34) 
Após a visita e o reconhecimento do espaço, Maneco e Oswaldo Aguiar realizaram o cadastramento de pessoas sem moradia para serem contemplados com lotes no futuro bairro. Segundo Osvaldo Aguiar (2009, p.44), "aí a gente organiza o pessoal, o pessoal topa. A gente conseguiu ainda cadastrar umas cento e cinquenta famílias “né”, aí: olha o seguinte nós vamos ocupar tal dia, marcamos o dia e tal [...]”.

Quando chegaram no local junto com os primeiros moradores, depois de superar a resistência inicial da polícia, começaram a limpar a área, e, para felicidades deles, perceberam que a área era maior do que tinham imaginado. À princípio, fizeram uma limpeza coletiva para, somente depois, ser realizado o sorteio dos lotes para os moradores. Cabe frisar que o bairro não foi ocupado apenas por pessoas do Pantanal, pois migraram pessoas de outros bairros e até mesmo de cidades vizinhas, como Forquilha e Meruoca.

Um desafio no processo de ocupação foi garantir a permanência da população na área mesmo antes de construírem as casas, Osvaldo Aguiar fala que:

Começamos a abrir a área "né", mas aí a gente disse: olha quem tiver, e já tinha preparado o grupo, aí quem vier "pra” cá vai ter que ficar aqui "né”, então tem que, mesmo que volte lá "pra" onde "tá" o ponto de levar as coisas, as coisinhas que tiver "né", mas nós já temos que ir abrindo a área e ir fazendo as caixinhas de papelão, de saco e tem que ficar aqui "né", então quer dizer eu fiquei "né" praticamente eu o Maneco ficamos uns quatro meses das nossas vidas lá "pra" consolidar porque a gente sabia que nós tínhamos que planejar... (OSVALDO AGUIAR, 2009, p.45).

Os primeiros moradores foram responsáveis por preparar o terreno para a construção das casas, tempo de muito esforço e suor, como pode ser percebido na fala de dona Teresinha Rodrigues de Lima, uma das primeiras moradoras do bairro:

Só tinha jurema preta, todo mato, tinha pau branco, todo mato tinha aqui e aí nós cortando "os mais fino as mulher" cortava os mais grosso era "os homem" e assim nós trabalhava até lá perto da fábrica de cimento, nós só saía de lá, nós cortava, o sol muito quente "né" aí nós ia queimar "cinco hora" da tarde, "seis hora" da tarde nós começava a queimar aí aqui "as mulhar" ia botando só mato era uma coivara mais medonha do mundo e nós "trabaiando" e assim nós "passemo" o tempo todinho "trabaiando" "pra" poder arranjar, tinha que trabalhar, os derradeiro já pegaram na garapa (LIMA, 2009, p. 26). 
Percebe-se que, segundo os depoimentos colhidos, os primeiros habitantes do bairro enfrentaram muitos desafios, tendo que superar a resistência da polícia, providenciar a limpeza do espaço e construir suas moradias. Também revelam que tiveram que conviver com a ausência de infraestrutura básica como abastecimento de água e distribuição de energia elétrica, mesmo o bairro tendo sido planejado pelos idealizadores da ocupação, conforme Osvaldo Aguiar:

[...] Esses bairros que surgiram na cidade de Sobral eu acho que o, o que foi planejado não-oficial foi a Vila União "né", os outros foram pensados depois "né", que foram planejados e a Vila União foi planejada não-oficial "né”, foi uma ocupação que a gente fez assim não oficial "né" assim que a gente pensou uma planta [...] (OSVALDO AGUIAR, 2009, p. 52).

Contam que o planejamento pelos ocupantes da área facilitou a instalação da energia elétrica e distribuição de água encanada no local, mostrando a força de sua agência na territorialização do lugar. Uma característica presente na configuração territorial do bairro é a presença de moradias de pequeno porte associadas a um aproveitamento excessivo do solo urbano, cenário comum nos bairros periféricos (figura 2).

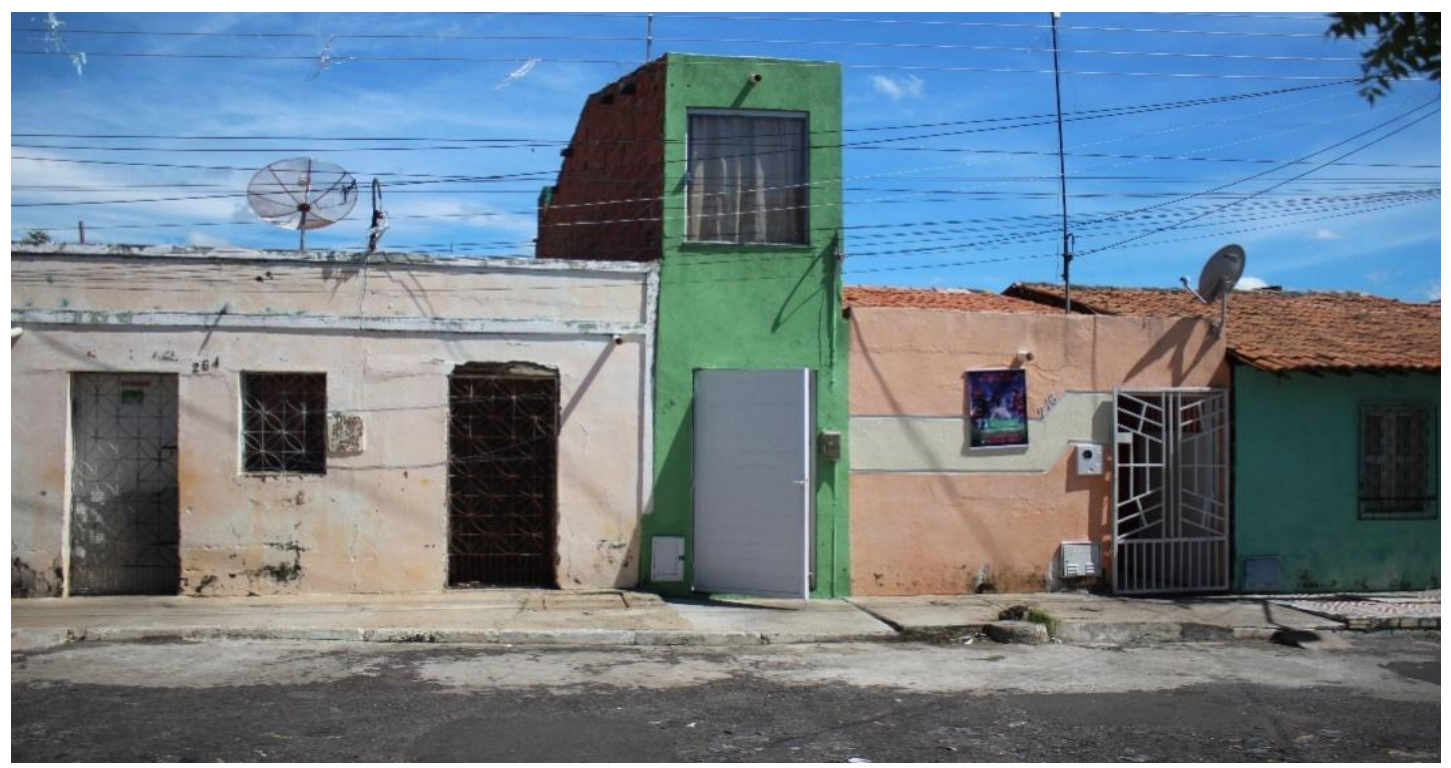

Figura 02 - Configuração das moradias no bairro Vila União.

Fonte: Silva (2018) 
A evolução de bairros periféricos é reflexo, por um lado, da ação dos próprios moradores que, pouco a pouco, vão melhorando suas residências e implantando atividades econômicas diversas. De outro lado, o Estado implanta alguma infraestrutura urbana, seja pela pressão dos moradores ou por interesses eleitoreiros (CORRÊA, 1989). Nesse contexto, a população do bairro já teve algumas conquistas estruturais como escola e posto de saúde (figura 3).
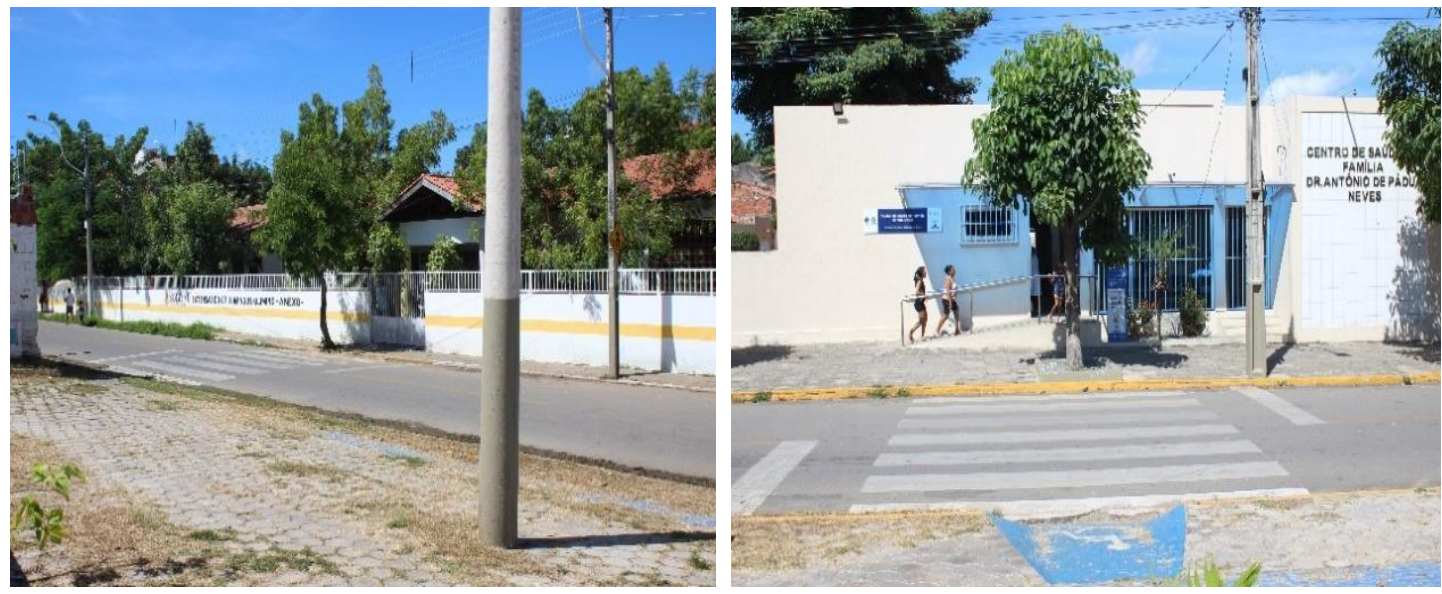

Figura 03 - Escola, do lado esquerdo e o Posto de Saúde da Família da Vila União. Fonte: Silva (2018).

Esses equipamentos urbanos quando utilizados pelos moradores do bairro são percebidos como geossímbolos. Os geossímbolos podem ser representados, através de pontos fixos, por exemplo, rochedos, árvores, construções, rios, desníveis, e itinerários, reconhecidos, cartografando no solo uma semiografia que é elaborada pelos signos, figuras e sistemas espaciais (CORRÊA, 2004).

Todavia, o bairro demanda, ainda, infraestrutura, uma vez que é perceptível a existência de esgoto a céu aberto e resíduos sólidos ocupando as margens das vias urbanas (figura 4), e, consequentemente, a presença de insetos que podem trazer danos à saúde da população do bairro. 

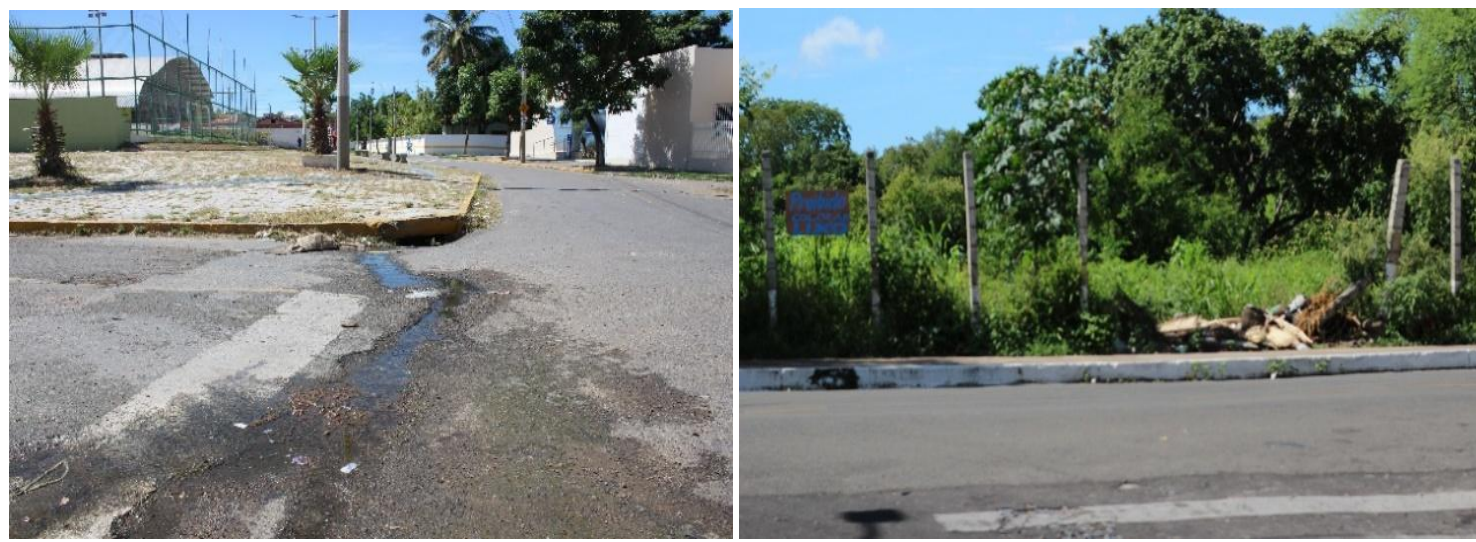

Figura 04 - Esgoto a céu aberto e lixo nas ruas do bairro Vila União. Fonte: Silva (2018).

Outro problema relatado nas entrevistas é a poluição atmosférica provocada pela fábrica de cimento presente no bairro (figura 5). Segundo o entrevistado Osvaldo Aguiar:

Cinco e meia seis horas da manhã você vê um, uma fumaça na cidade toda aqui que é o pó da fábrica de cimento, não consegue subir "né" lá, superar quando "tá" a neblina, muito neblinado, então a gente fez é, nós fizemos um abaixo-assinado da comunidade pedindo "pra" discutir, que a prefeitura tome uma posição "né" e que a fábrica também tome uma posição e tal [...] (OSVALDO AGUIAR, 2009, p. 60)

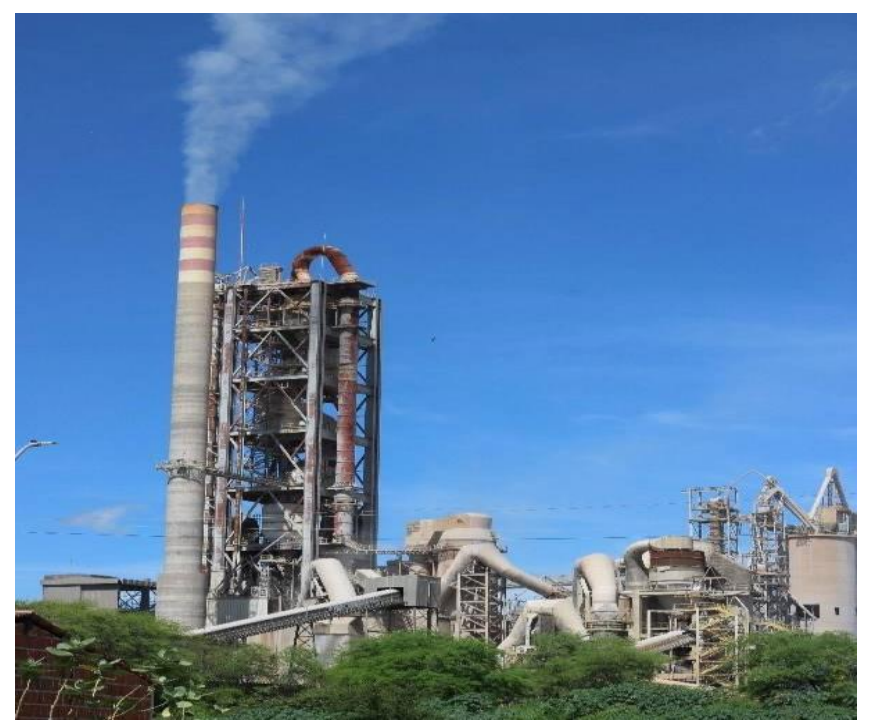

Figura 05- Poluição atmosférica provocada pela fábrica de cimento presente no bairro Vila União. Fonte: Silva (2018). 
A fábrica também polui a paisagem (poluição visual) e emite ruído (poluição sonora) que incomoda a população local. Além de sofrer com a poluição e ausência de serviços básicos a comunidade ainda convive com a violência, problema social presente nas cidades brasileiras.

\section{Vila União: Meu bairro! Meu lugar!}

Para entender a relação da comunidade com o espaço e suas experiências é imprescindível conhecer o conceito de bairro que aqui é relacionado à concepção de lugar. Para entender o que é um bairro vale a pena frisar que não dá para definir com precisão o que realmente é do ponto de vista conceitual e territorial. Não é nada mais que uma construção arbitrária e administrativa por parte do poder público, virtual e livre por parte do morador. Ao mesmo tempo é uma convergência e divergência de extensões fluidas por parte do morador que não corresponde a um território homogêneo de ordem moral, religiosa, ideológica, social e econômica, apesar dos esforços dos moradores em criar consensos sociais. Os seus limites são imprecisos quando comparados aos que são definidos pelo poder público e aos que são falados pelos moradores.

O bairro poderia ser pensado também a partir de um determinado feixe de relações sociais formando uma "comunidade", em função da pessoalidade fundada em forte reconhecimento social entre seus moradores. Duarte (2002) chama a atenção, e corrobora-se aqui, que faz sentido pensar que o bairro, especialmente o periférico que é formado por casas conjugadas, pequenas, com estrutura precária, não favorecendo a "privacidade" do morador, como supostamente habitado por pessoas que partilham de sentimentos recíprocos, produzindo um suposto consenso ou modo comum de perceber e agir no espaço. Entretanto, não é bem assim que empiricamente está se constituindo o espaço. Os conflitos, diferenças internas e dissensos sociais estão presentes no bairro, ao mesmo tempo que acompanhados de investimentos na consolidação de identidades.

Nesse caso, o conceito central talvez não seja o de bairro, mas o de lugar. Esta categoria geográfica apareceu como conceito-chave na evolução do pensamento geográfico no contexto da Geografia Humanista, na década de 1970. Nesse contexto, percebe-se duas acepções principais sobre o conceito de lugar, sendo estas consideradas em dois de seus eixos epistemológicos, o da Geografia Humanística, que considera lugar como produto da experiência humana; e a Geografia Radical ou dialética 
marxista, em que o lugar assume uma compreensão enquanto espaço de singularidade constituída por dinâmicas associadas aos meios de produção da vida material (STANISKI, KUNDLASCH, PIREHOWSKI, 2014).

O lugar é onde estão as referências pessoais e as subjetividades que direcionam as diferentes formas de perceber e constituir a paisagem e o espaço geográfico. Tratase na realidade de espacialidades carregadas de laços afetivos com os quais a sociedade desenvolve ao longo da vida na convivência com o lugar e com os outros (STANISKI, KUNDLASCH, PIREHOWSKI, 2014).

O conceito de lugar assume um caráter subjetivo, uma vez que cada indivíduo traz já a memória e uma experiência direta com seu espaço, com o seu lugar, pois é a partir desse envolvimento com o local agenciado pela territorialização dos indivíduos que se adquire tal pertencimento. Para Santos (2006, p. 212), "Os lugares são vistos como intermédio entre o mundo e o indivíduo".

Michel de Certeau ajuda a compreender o lugar para além da dinâmica da reprodução da vida material, sem descartá-la, ampliando sua definição. Enfatiza como cada indivíduo vê e define o lugar. Assim, conforme Certeau:

Um lugar é a ordem (seja qual for) segundo a qual se distribuem elementos nas relações de coexistências. Aí se acha, portanto, excluída a possibilidade, para duas coisas, de ocuparem o mesmo lugar. Aí impera a lei do "próprio" e distinto que define. Um lugar é, portanto, uma configuração instantânea de posições. Implica uma indicação de estabilidade. (CERTEAU, 2008, p. 201).

Nesse caso, o autor valoriza a agência cotidiana dos indivíduos para territorialização do lugar, fugindo da armadilha da propriedade estável de características espaciais. O espaço, para o autor, é movimento, tensão e contradições instáveis e, durante este movimento, os indivíduos, através de suas astúcias e práticas cotidianas, vão criando propriedades, mesmo que contextuais e fluidas, sem consistências definitivas, que definem lugares, e o defendem como território deles. São movimentos contraditórios que permitem visualidades a territorialização do espaço.

Já Yu-Fu-Tuan associa o conceito de lugar às relações de afetividade e sentimento das pessoas com o meio em que vivem. O lugar tem muitos significados que são atribuídos pelas pessoas e traduz os espaços com os quais as pessoas têm vínculos mais afetivos e subjetivos que racionais e objetivos (TUAN, 1975). Acrescentamos, com base em Certeau, que o lugar e o espaço não podem ser pensados somente enquanto 
sentimentos aplicados à territorialização. São também agências pragmáticas, acionadas no tempo do cotidiano, visando interesses que não passam necessariamente somente por sentimentos e emoções, mas envolvem também dinâmicas que passam por materialidades e imaterialidades, conflitos e sinergias muito pouco controláveis por cada indivíduo, apesar dos esforços para a efetivação deste controle.

Os relatos das entrevistas podem ser muito bem utilizados para identificar o lugar potencial produzido pelos indivíduos, pois mostram os espaços com os quais as pessoas têm vínculos mais afetivos e subjetivos, assim como também pragmáticos, racionais e objetivos. Portelli (1997, p.31) afirma que "o único e precioso elemento que as fontes orais têm sobre o historiador, e que nenhuma outra fonte possui em medida igual, é a subjetividade do expositor". Para a geografia, este tipo de fonte mostra mais um percurso no espaço do que um mapa fixo de pontos estáveis.

Nesse contexto, é notório nas entrevistas e no documentário, que mesmo diante dos desafios enfrentados pela comunidade, os moradores apresentam uma grande identificação e afetividade com o bairro, ou seja, a Vila União é o lugar de seus moradores. Para Tuan (1983, p.83), "quando o espaço nos é inteiramente familiar, torna-se lugar”. Entretanto, deve-se lembrar aqui que a narrativa também tem um caráter pragmático de causar um efeito no interlocutor. Assim, não podemos interpretar que os moradores sustentam seus argumentos em crenças ou que suas falas são objetivamente uma identificação da afetividade com o lugar. São potências e agências que visam causar este efeito em quem escuta.

Esse efeito de afetividade com o lugar pode ser percebido nas palavras da dona Minervina de Melo Vasconcelos (2009, p. 16), ao dizer: "eu acho bom demais a minha rua”, e Terezinha Rodrigues de Lima (2009, p.24) quando indagada se gostava do antigo local que morava, ao que respondeu: "gostava, mas aqui eu gosto mais". Observamos que para ambas o afeto pelo bairro está associado à conquista pela moradia, na ótica de Carlos:

A produção espacial realiza-se no plano do cotidiano e aparece nas formas de apropriação, utilização e ocupação de um determinado lugar, num momento específico e, revela-se pelo uso como produto da divisão social e técnica do trabalho que produz uma morfologia espacial fragmentada e hierarquizada. Uma vez que cada sujeito se situa num espaço, o lugar permite pensar o viver, o habitar, o trabalho, o lazer enquanto situações vividas, revelando, no nível do cotidiano, os conflitos do mundo moderno (CARLOS, 2007, p. 20). 
Nas narrativas também foi perceptível as diferenças internas na percepção do lugar pela comunidade, uma vez que cada indivíduo vê e percebe o bairro a partir de suas experiências. A ligação de Osvaldo e Maneco com o bairro está associada à mobilização política comunitária como pode ser percebido na fala de Osvaldo Aguiar (2009) sobre o processo de ocupação do bairro: “a gente começa a se preparar e nós olha nós temos que formar um grupo, então todo dia cinco horas a gente tinha uma reunião do grupo "né" da, tinha um grupo lá da liderança "né" e a gente tinha uma reunião todo dia cinco horas "né”".

Também podemos perceber que algumas narrativas falam que no contexto de organização e ocupação da Vila União ocorreram conflitos por terreno entre os sujeitos ocupantes, fato que pode ser percebido na fala da moradora Francisca da Silva Arruda:

Pois sim, pois sim, aí eu fui lavar roupa aqui numa barragem $[\ldots]$ aí um dia eu cheguei aí quando eu avistei aqui nesse altinho eu vinha descendo aí quando eu vi o "caboco" né, aí marcando, aí eu deixei a trouxa de roupa lá na minha irmã aí eu digo: seu Zé me diga aqui uma coisa o que é que você "ta" fazendo aqui nesse terreno? Não é meu terreno, eu digo: eu "to" marcando aqui como deve, me diga aqui uma coisa como é que a pessoa ganha um terreno duas vezes o terreno é meu! Aí ele disse: não! Eu "to" marcando... Eu digo: pois se você vai marcar eu vou ficar aqui é você e eu que vai, vai ficar com o terreno porque o terreno é meu "ta" aqui marcado já tem meu papelzinho botando o número da quadra aí ele, aí ele disse: não! , aí eu: não mais eu digo: pois você vai ficar aqui aí ele ficou desconfiado minha "fia” aí eu acho que eu só vi esse homem nesse dia e não vi mais (ARRUDA, 2009, p. 20).

Os moradores da Vila União apresentam em suas narrativas uma potência de identificação com o local de vivência, pois insistem em falar da afetividade e o sentimento de pertencimento da comunidade com o lugar, segundo alguns, expresso em suas práticas e modos de vida. Entretanto, as justificativas para esse gostar podem variar. Um expõe que o motivo do afeto é a casa que mora, interesse pragmático expresso como sentimento, como no caso de Minervina e Terezinha. Outro motivo é o sentimento de "comunidade", seja ele pensado como politicamente agenciado, como no caso de Maneco e Osvaldo. Outro motivo pode ser fundado na ideia de se estar perto de seus iguais, apesar dos conflitos abertos presentes na territorialização do espaço, materializados na "guerra" entre grupos de jovens rivais e da violência urbana. Assim, percebe-se que o bairro é produzido e produto das relações sociais que se estabelecem 
no território em que vivem e constroem. É um território carregado de contradições e movimentos de territorialização e desterritorialização constantes que não sustentam qualquer tentativa de estabilidade e fixidez, apesar de não as descartar como desejo e agência.

\section{Considerações Finais}

A "Princesa do Norte" ou Sobral, não oferece moradia nos bairros elitizados para todos os seus habitantes, expelindo os migrantes pobres para as áreas periféricas da cidade. Essa periferia abriga pessoas vindas de vários lugares em busca de uma "vida melhor", em comparação àquela experimentada no seu lugar de origem.

Como exposto, o bairro Vila União surgiu nesse contexto de ineficiência do poder público que não garante a uma parte da população o acesso à moradia, um dos direitos básicos assegurados na Constituição Federal, e mobilização popular em busca da solução para este problema.

Conforme a memória dos moradores sobre o processo histórico de ocupação do bairro, o que hoje consiste em um local densamente povoado, era uma área desabitada. Quando os primeiros moradores chegaram tiveram que limpar o terreno, marcar os lotes e construir as primeiras casas, com base em um planejamento urbano feito por integrantes do movimento social que organizou o processo. Era um planejamento ainda incipiente, mas fundado na lógica do arruamento regular, linear, formando quadras. Nesse quadro, as narrativas dos moradores mais antigos ressaltam seu "heroísmo" na conquista do território, mostrando suas trajetórias, dificuldades e soluções encontradas. As dificuldades circulam entre conflitos de interesses individuais, ausência de distribuição de água, falta iluminação pública, dentre outros.

Depois de ocupado o território, a gestão municipal se achou na obrigação de atender as demandas criadas pela ocupação. A população acabou por conquistar alguma infraestrutura básica como ginásio poliesportivo (Estação da Juventude), escola e posto de saúde, além de distribuição de água encanada e energia elétrica. Porém, é um bairro que ainda demanda de muitos serviços públicos, como um melhor saneamento básico, além de conviver com a violência urbana e danos provocados pelas poluições da fábrica de cimento. 
Cabe salientar, que mesmo diante das dificuldades enfrentadas pelos moradores da Vila União, percebe-se em suas narrativas os laços de afetividade com o meio em que vivem, apesar de os critérios para justificar esse afeto sejam variados. Por fim, embora a comunidade receba influência exógena, o bairro é um espaço produzido e reproduzido pelas ações e intencionalidade da população local que, através de suas agências cotidianas, territorializam o espaço geográfico, ao mesmo tempo mostrando conflitos e tentativas de consenso social sobre o território e o lugar desejado. Para a geografia, esse movimento que parece contraditório, enriquece a análise e diversifica os princípios metodológicos que procuram uma compreensão deste processo. É o movimento da territorialização do espaço que se pretende aqui continuar a seguir.

\section{NOTAS}

* Graduado em licenciatura em Geografia pela Universidade Federal do Piauí (UFPI), mestrando em Geografia pela Universidade Estadual Vale do Acaraú (UVA) e professor de Geografia da Secretaria da Educação do Ceará - SEDUC/CE. Email para contato: nildemarpsilva@gmail.com

† Graduado em Ciências Sociais (Bacharelado) pela Universidade Federal do Ceará (UFC), mestrado em Sociologia pela Universidade Federal do Ceará (UFC), doutorado em Sociologia pela Universidade Federal do Ceará (UFC), Pós-Doutorado em Estudos Culturais no Programa Avançado em Cultura Contemporânea da Universidade Federal do Rio de Janeiro (UFRJ) e professor doutor do quadro permanente do Mestrado Acadêmico em Geografia da Universidade Estadual Vale do Acaraú - UVA. Email para contato: nilsonalmino@hotmail.com

$1 \mathrm{O}$ filme pode ser visto em https://vimeo.com/82281116.

${ }^{2} \mathrm{O}$ LABOME é um arquivo público de documentos orais e visuais, de apoio à investigação científica, vinculado ao Mestrado Acadêmico em Geografia e ao Curso de Ciências Sociais do Centro de Ciências Humanas (CCH) da Universidade Estadual Vale do Acaraú (UVA).

3 O termo "Distinta" era concedido a Vilas colonizadas predominantemente por população branca, enquanto o termo "real" refere-se à concessão da condição de Vila por parte do próprio Rei. (Cf.FREITAS, 2000).

${ }_{4}^{4}$ As aspas nas citações dos entrevistados indicam que a oralidade foi preservada

\section{REFERÊNCIAS BIBLIOGRÁFICAS}

AGUIAR, Osvaldo. (depoimento, 26.04.09). Sobral, Laboratório de Memórias e Práticas Cotidianas, 2009.

ARRUDA, Francisca da Silva. (depoimento, 08/09/09). Sobral. Laboratório de Memórias e Práticas Cotidianas, 2009.

CARLOS, A. F. A. O lugar no/do mundo. São Paulo: FFLCH, 2007.

CERTEAU, Michel de. Relatos de espaço. In: A invenção do cotidiano: artes de fazer. Vozes: Petrópolis, 1998, p. 1999-217. 
CORRÊA, Roberto Lobato. O espaço urbano. São Paulo: Ática, 1989.

CORRÊA, A. de. M. Irmandade da Boa Morte como manifestação cultural afro-brasileira: de cultura alternativa à inserção global. 2004. Tese de doutorado (Geografia) - Universidade Federal do Rio de Janeiro, Rio de Janeiro, 2004.

DELEUZE, Gilles \& GUATTARI, Félix. "Devir-intenso, devir-animal, devir-imperceptível”. in.: Mil platôs: capitalismo e esquizofrenia. vol.4, Rio de Janeiro, Editora 34, 1997.

DUARTE, Adriano Luiz. Os sentidos da comunidade: notas para um estudo sobre bairros operários e identidade cultural. Trajetos Revista de História da UFC. Fortaleza: Departamento de História da UFC, 2002, v.1, n.2, pp.103-113.

FREITAS, N. A. de. Ação, efeito e manobras: o "artefato primoroso" da monumentalização de Sobral e seus usos no campo político. In: Júnior, M. M; Freitas, N. A. de; Holanda; V. C. C. de. (Org.). Múltiplos olhares sobre a cidade e o urbano: Sobral e Região em foco. Sobral: UECE/UVA, p.185-210.

HOLANDA, V. C. C. de. Modernizações e espaços seletivos no Nordeste brasileiro. Sobral: conexão lugar/mundo. 2007, São Paulo, 280f. Tese (Doutorado) - Programa de pós-graduação em Geografia Humana do Departamento de Geografia da Faculdade de Filosofia, Letras e Ciências Humanas. Universidade de São Paulo, São Paulo, 2007.

JÚNIOR, M. M. Da fazenda Caiçara, nos "sertões do Norte", à cidade de Sobral: reconstruindo espacialmente o processo da expressão regional. In: Júnior, M. M; FREITAS, N. A. de; Holanda; V. C. C. de. (Org.). Múltiplos olhares sobre a cidade e o urbano: Sobral e Região em foco. Sobral: UECE/UVA, p.145184 .

LIMA, Terezinha Rodrigues de. (depoimento, 26.08.09). Sobral, Laboratório de Memórias e Práticas Cotidianas, 2009.

PORTELLI, Alessandro. “o que faz a história oral diferente”. Projeto-História. São Paulo. 1997.

SALES, T. B. Trabalhadores da fábrica de tecidos de Sobral: muitas histórias e outras memórias. Revista Historiar-Universidade Estadual Vale do Acaraú. Sobral, v.4. n. 4, p.1-15, jan./jun. 2011.

SANTOS, M. A Natureza do Espaço: técnica e tempo, razão e emoção- $4^{\mathrm{a}}$ Ed. $2^{\mathrm{a}}$ reimpressão. São Paulo. Editora Universidade de São Paulo, 2006.

SOUZA (MANECO), Emanuel Rodrigues. Emanuel Rodrigues de Souza. (depoimento, 10.08.2004). Sobral, Laboratório de Memórias e Práticas Cotidianas, 2005.

SPÓSITO, M. E. B. Capitalismo e urbanização. 10. ed. São Paulo: Contexto; 2000.

VASCONCELOS, Minervina de Melo. (depoimento, 05.11.09). Sobral, Laboratório de Memórias e Práticas Cotidianas, 2009.

STANISKI, A; KUNDLATSCH, C. A; PIREHOWSKI, D. O conceito de lugar e suas diferentes abordagens. Revista perspectiva geográfica-UNIOESTE. Cascavel, v.9, n.11, p. 1-19, 2014.

TUAN, Y. -F. Espaço e Lugar: a perspectiva da experiência. São Paulo: DIFEL, 1983.

Place: na Experiential Perspective. Geographical Review, 65, pág. 151-165, 1975. 


\section{VILA UNIÃO: NEIGHBORHOOD, MEMORIES AND TERRITORIALIZATION}

ABSTRACT: THIS PAPER PRESENTS THE OCCUPATION HISTORY VILA UNIÃO NEIGHBORHOOD, SOBRAL CE, FROM THE MEMORIES OF ITS RESIDENTS, THINKING THEIR AGENCIES IN THE TERRITORIALIZATION OF THE PLACE. THUS, IT'S INTENDED TO IDENTIFY THE EXPERIENCES AND RELASTIONSHIPS OF THE RESIDENTS BELONGING TO THE NEIGHBORHOOD FROM THE NARRATIVES. THE METHODOLOGY USED WAS BIBLIOGRAPHIC, FIELD RESEARCH AND, SPECIALLY, ORAL HISTORY. FINALLY, DESPITE THE DIFFICULTIES FACED BY RESIDENTS OF THE NEIGHBORHOOD, THE AFFECTIVE BONDS WITH THE ENVIRONMENT IN WHICH THEY LIVE ARE PERCEPTIBLE IN THEIR NARRATIVES, ALTHOUGH THE CRITERIA TO JUSTIFY THIS AFFECTIVITY ARE VARIED.

KEY WORDS: NEIGHBORHOOD. TERRITORIALIZATION. MEMORIES. ORAL HISTORY.

\section{VILA UNIÃO: BAIRRO, MEMORIAS Y TERRITORIALIZACIÓN}

RESUMEN: EL PRESENTE TRABAJO PRESENTA LA HISTORIA DE OCUPACIÓN DEL BARRIO VILA UNIÃO, SOBRAL - CE, A PARTIR DE LAS MEMORIAS DE SUS HABITANTES, PENSANDO SUS AGENCIAS EM LA TERRITORIALIZACIÓN DEL LUGAR. ASÍ, SE PRETENDE IDENTIFICAR LAS VIVENCIAS Y LAS RELACIONES DE PERTENENCIA DE LOS MORADORES CON EL BARRIO A PARTIR DE SUS NARRATIVAS. LA METODOLOGÍA UTILIZADA FUE INVESTIGACIÓN BIBLIOGRÁFICA, DE CAMPO Y, ESPECIALMENTE, LA HISTORIA ORAL. POR ÚLTIMO, INCLUSO ANTE LAS DIFICULTADES ENFRENTADAS POR LOS MORADORES DEL BARRIO, ES PERCEPTIBLE EN SUS NARRATIVAS. LA METODOLOGÍA UTILIZADA FUE INVESTIGACIÓN BIBLIOGRÁFICA, DE CAMPO Y, ESPECIALMENTE, LA HISTORIA ORAL. POR ÚLTIMO, INCLUSO ANTE LAS DIFICULTADES ENFRENTADAS POR LOS MORADORES DEL BARRIO, ES PERCEPTIBLE EM SUS NARRATIVAS LOS LAZOS DE AFECTIVIDAD CON EL MEDIO EN QUE VIVEN, A PESAR DE LOS CRITERIOS PARA JUSTIFICAR ESA AFECTIVIDAD SER VARIADOS.

PALABRAS CLAVES: BARRIO. TERRITORIALIZACIÓN. MEMORIAS. HISTORIA ORAL. 